\title{
Epicuticular wax concentration on Syzygium myrtifolium leaves
}

\author{
Mohd Nor Ammar Mohd Isa ${ }^{*}$, Nik Muhamad Abd. Majid ${ }^{2}$, Sase Hiroyuki ${ }^{3}$, \\ Osumanu Haruna Ahmed ${ }^{1}$, Franklin Ragai Kundat ${ }^{1}$, Roland Kueh Jui Heng ${ }^{1}$ \\ ${ }^{1}$ Faculty of Agriculture and Food Sciences, Universiti Putra Malaysia Bintulu Sarawak Campus, P.O. Box 396, \\ Jalan Nyabau, 97008 Bintulu, Sarawak, Malaysia \\ ${ }^{2}$ Institute of Tropical Forestry and Forest Products, Universiti Putra Malaysia, 43400 Serdang, Selangor, \\ Malaysia. \\ ${ }^{3}$ Ecological Impact Research Development, Asia Centre for Air Pollution Research, 1182 Sowa Nishi-ku \\ Niigata-shi, 950-2144 Japan
}

\begin{abstract}
The pollution issues are a pervasive and increasing threat to human and forest ecosystem. Plants have been recognised as a method to reduce pollution. However, leaf is the most sensitive organ to pollution where changes in leaf morphological, physiological, anatomical and biochemical can occur. This study was conducted to determine the quantity of epicuticular wax on Syzygium myrtifolium leaves in urban, suburban and industrial areas. Three trees were selected in each of the study sites and new leaves on the branch was marked. $5 \mathrm{~g}$ of samples were collected for analysis. Leaf surface particles were extracted by using $20 \mathrm{ml}$ of chloroform in conical flask and was left overnight for hardening where weight were recorded. Data analysis showed that the mean epicuticular wax ranged from 267.2-680.7 $\mu \mathrm{g} / \mathrm{m}^{2}$ with a mean increment of 309.6-950.7 $\mu \mathrm{g} / \mathrm{m}^{2} / \mathrm{yr}$. The epicuticular wax concentration on S. myrtifolium leaves was significantly higher in industrial areas compared to those in the urban and suburban areas. S. myrtifolium at industrial areas are in the open and subjected to direct sunlight and also responding to stress caused by the air pollutions. The low concentration of epicuticular wax was recorded on S. myrtifolium leaves in urban area. These trees are subjected to high concentration of pollutants especially from exhaust emissions and possible is due to the aerosol deposition which have been carried by the wind. This initial study reveal that the level of physiological stress on the trees in industrial, suburban and urban areas are at a different scale where the levels of air pollution is different. Understanding the tree traits are important to capitalize their role as bio filters. This study provide the baseline data for future study where the relationship between the particulate matters deposited on the tree canopy and the tree trait could be explained.
\end{abstract}

Keywords: Epicuticular wax, industrial area, suburban area, Syzygium myrtifolium, urban area.

\section{Introduction}

Industrialization and urbanization is a global phenomenon and has transformed urban socially, economically and environmentally. Positive development also resulted in a degradation of the environment quality. Developing countries, in the case of India, has over 26.5 million vehicles which resulted in several environmental pollution problems [1] while in a review, the forests of East Asian region having the same fate [2]. The pollution issues are a pervasive and increasing threat to human and the forest ecosystem. This is because pollutants can travel long distances from their sources [3].

Plants have been recognised as a method to reduce pollution [4]. This is due to the fact that urban forest ecosystem plays an important role as interface between the atmosphere and forest ecosystems [5]. Hence, trees can improve quality urban life where they act as biological absorbers of pollutants [4], especially removing particulate matter and their associated semi-volatile organic compounds from the atmosphere [6]. The ability of plant species to mitigate these pollutants varies significantly due to differences in their leaf surface characteristics such as epicuticular wax, cuticle, epidermis, stomata and trichomes [7]. Epicuticular wax in plants is a wax coat covering the outer surface of the plant cuticle. It functions as a UV light reflector, decrease surface wetting and moisture loss, self-cleaning surface and anti-climb surface as in Macaranga spp. [8; 9]. Therefore, epicuticular wax is an important structural element of the leaf surface that facilitates in the plants and environment interaction [10].

In polluted areas, leaf is the most sensitive organ to pollution [11] as pollutants are deposited on the leaves surface. Many studies showed that pollutants cause alteration to the leaf morphological, physiological, anatomical and biochemical. Species that react to presence of air pollutants showing visible symptoms can be used as bio indicators. Studies found that epicuticular wax on the conifer needles are degraded due to the effects of air pollutions [12; 13], and changes in its structure [14]. The rate of wax erosion correlates with the level of air pollution. This causes changes needle or leaf wettability and rain retention. In addition, delay development 
and rapid erosion of epicuticular wax were recorded in needles which are subjected to simulated acid-rain test and aerosol particles $[15 ; 13]$. These changes increases the cuticular transpiration rate and affect plant growth [16]. However, larger quantity of epicuticular wax occurs when trees are under drought condition [17].

The urban forest ecosystems in Bintulu, Sarawak showed the potentially problems in relation to pollutions because of the increase use of oil products and the physical development due to high investment on heavy industries. Among the common trees in the urban ecosystem in Malaysia are such as Kelat paya, merawan, kayu manis, angsana and rain tree [18]. Syzygium myrtifolium or locally known as Kelat Paya is from the family Myrtaceae. It has a dense canopy with a mix of green and red-maroon leaves. However, information in relation to the epicuticular wax of tropical trees in this country is rather limited. Some efforts were recorded where [19] conducted chemical constituent of wax lipids from leaf surfaces of 10 common roadside trees in Kuala Lumpur, Malaysia while [20] did similar analysis for Litsea spp in Sarawak, Malaysia.

This study was conducted to determine the quantity of epicuticular wax on S. myrtifolium leaves. The leave samples were collected from trees in various locations in Bintulu District where some are near to the oilbased industrial estates (Kidurong), wood-based industrial estates (Kemena), town centre and suburban area (Stadium Muhibbah and UPMKB). Information will help to provide understanding on the effects of anthropogenic factors on the concentration of wax on the leaves.

\subsection{Study sites}

\section{Materials and Methods}

The study was conducted in various locations in the Bintulu District, Sarawak, Malaysia. Bintulu has been designated to be an industrial city by the State Government of Sarawak. Major physical development is occurring which may elevate certain environmental issues. In this study six sites were selected where 3 sites are located near the industrial estates, 1 in urban area and 2 in suburban areas. Site 1 (Sekolah Kebangsaan Asykirin), Site 2 (Vocational Bintulu) and Site 6 (Sekolah Menengah Kai Dee) are near to the industrial estates. Sites 1 and 2 are on the northern site (Fig 1) which is in the Kidurong Industrial Area (KINDA) and Kidurong Light Industrial Estate (KLIE). The main industries are the oil and gas processing industries, palm oil refinery, wood based, glue and cement factories including a power plant. As for Site 6 (southern side) is near to timberbased industries in the Kemena Industrial Estate (KIE). Site 3 (Stadium Muhibbah), Site 4 (Universiti Putra Malaysia Bintulu Sarawak Campus) is considered as suburban area while Site 5 (St Anthony Church) in located in the town centre (Fig. 1) is considered as urban area.

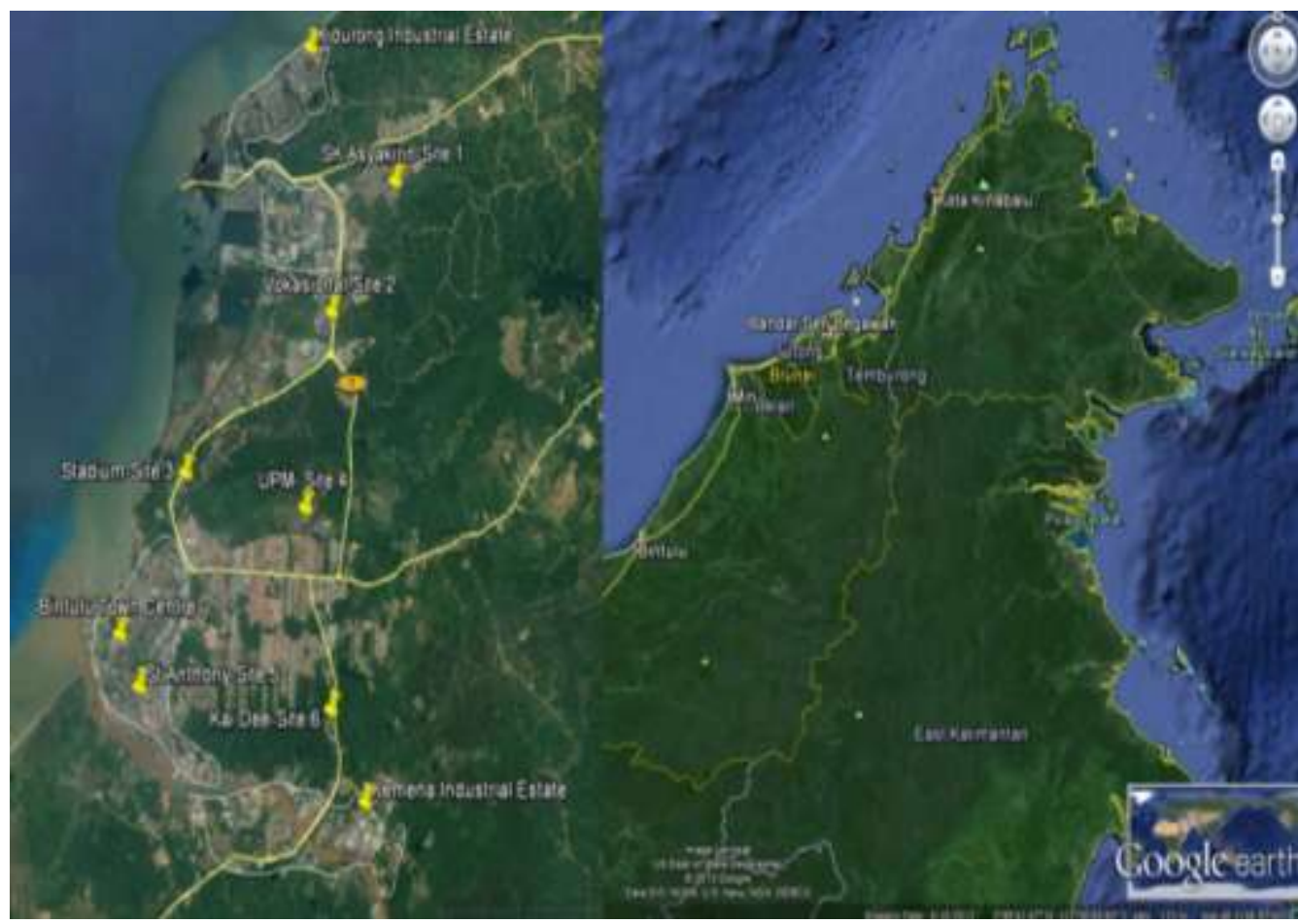

Figure. 1. The location of study sites in this study

\subsection{Leaf samples.}

The common tree species found in the six study sites was Syzygium myrtifolium. On May 2015, three trees were selected in each of the study sites and new leaves on the branch was marked. The new leaves are 
indicated by the maroon-coloured leaves. Leaves were harvested in January and March 2016. Leaves from the 3 branches are composited and $5 \mathrm{~g}$ of samples were collected for analysis. At the laboratory, the leaf samples were washed with de-ionized water and gently dried under room temperature on the filter paper. Leaf-surface particles were extracted by using $20 \mathrm{ml}$ of chloroform in conical flask for 30 seconds to dissolve epicuticular wax on the leaf surface. The epicuticular wax was left overnight for hardening and the weight were recorded.

\subsection{Data analysis}

Analysis of variance was used using the SAS for window version 9.13 software. This was used to determine the significant differences epicuticular wax concentration among the study sites. Results which showed significant differences in means were differentiated using Tukey's Range Test.

\section{Results and Discussion}

The mean epicuticular wax ranges from 267.2-680.7 $\mu \mathrm{g} / \mathrm{m}^{2}$ (Fig. 2) with a mean increment of 309.6$950.7 \mu \mathrm{g} / \mathrm{m}^{2} / \mathrm{yr}$ (Fig. 3). There is relative little information data regarding to the epicuticular wax concentration on the urban trees in Malaysia to compare to this study. As a guide, studies conducted by various researchers suggested that trees that are found in low relative humidity with a range of 20-30\% has higher epicuticular wax than those found in high relative humidity condition (98\%). It is also found that the wax thickness is higher during warm, dry site than on cool, moist site. Environmental factors such as light intensity, relative humidity, temperatures are important factor in inducing wax development [21].

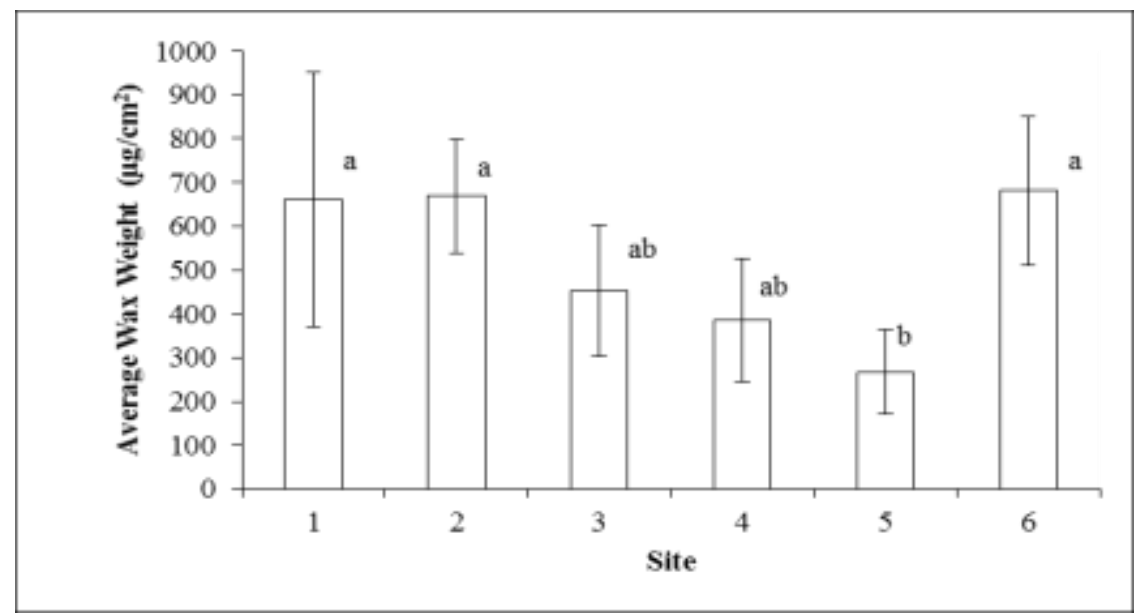

Note: Different alphabets denotes significant differences $\mathrm{p} \leq 0.05$ using Tukey Range Test

Figure 2. The distribution of average wax concentration at different study sites

The epicuticular wax concentration on Syzygium myrtifolium leaves was significantly higher in industrial areas compared to those in the urban areas. S. myrtifolium at industrial areas are in the open and subjected to direct sunlight. The annual accumulation of epicuticular wax was higher on S. myrtifolium leaves located near the industrial zones compared to the urban areas. It is difficult to find enough data to compare to this study. This is because there is relatively lack of studies in the aspect of changes in accumulation of epicuticular wax that can occur during the year. However, there are studies conducted on Dounglas-fir's needles in Washington and Oregon, USA, found that there are significant increment in wax thickness during the year from late June/early July to early November [22]. 


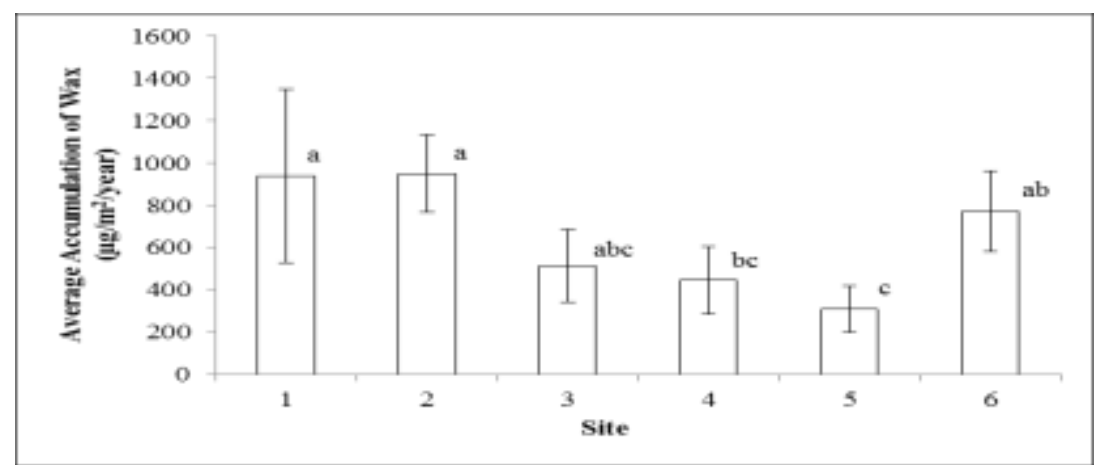

Note: Different alphabets denotes significant differences $\mathrm{p} \leq 0.05$ using Tukey Range Test

Figure 3. The mean annual accumulation of wax on S. myrtifolium at different sites

The possibilities of heat related stress are experienced by S. myrtifolium in that location. This is because there is an increasing trend in the average max-min temperature recorded in Bintulu for 2006 where the mean air temperature ranged from $23.7-31.5^{\circ} \mathrm{C}$ compared to $23.8-32.2^{\circ} \mathrm{C}$ in 2013 [23; 24]. Generally, epicuticular wax production increases in stress condition or drought-stresses plant [25]. This will enhance the plant tolerant to high temperature stress, disease, insects and moisture stress. Roadside trees experiencing water deficiency due to heat related stress, therefore a well-developed epicuticular wax layer is crucial. This is to increase the efficiency of stomatal functions, reduce water loss, and any change in the original morphological structure will make these plants more sensitive to water stress $[1 ; 26]$.

However, there is another possibility that the $S$. myrtifolium trees is responding to stress caused by the air pollutions. Sekolah Kebangsaan Asykirin and Vocational Bintulu is near to the petrochemical and refinery plants at the northern region whereas Sekolah Menengah Kai Dee is near to the wood factories. Similar pattern has been recorded on Cryptomerica japonica tree in Japan which is near to an electrochemical plant. Epicuticular wax concentration showed an increase in $10 \%$ where it is a physiological response to stress caused by the air pollutions [17]. Studies suggested that particulate matter (PM) deposited on the epicuticular wax can cause physiological and morphological impacts including increased cell alkalinity, photosynthetic inhibition, leaf senescence, stomatal damage, and reduced growth and yield [27; 28].

The low concentration of epicuticular wax was recorded on $S$. myrtifolium leaves in urban area. These trees are subjected to high concentration of pollutants especially from exhaust emissions. Similar pattern has been recorded in India, where studies found that in Asparagus racemosus, Azadirachta indica, Bougainvillea spectabilis, Cassia fistula, Ficus religiosa, Nerium indicum, Polyalthia longifolia and Thevetia neriifolia, the epicuticular wax lost its original shape, got disorganized and subsequently eroded. This is probably due to the continuous fumigation of the plants with exhaust emissions under high temperatures $\left(30-50^{\circ} \mathrm{C}\right.$ approx.), owing to the close proximity of the plants to the sources of pollution [1]. Studies using scanning electron microsopical (SEM) found that Norway spruce needles, Finland showed deleterious effects of exposure on the epistomatal wax of needles where the epicuticular wax around the stomata was injured for trees along the highway [14]. These fuel combustion created sulphur dioxide and nitrogen oxides which are responsible for the formation of acid rain. The acid rain has been reported to be able to erode epicuticular wax [29].

The other possibility is due to the aerosol deposition which have been carried by the wind. The wind rose chart for Bintulu showed several wind directions (Fig. 4). Aerosol and other pollutants from the industrial area in the northern region could be blown by the wind to the south-west region when the centre town is located. It has been reported that excessive aerosol deposition causes wax degradation [13]. Aerosol has shown to have reduced the plant drought tolerance especially in pines trees [30]. The concern would be that the level of aerosol concentrations have increased globally due to industrialization and wind erosion by land use changes [31; 32]. This will create another issues relating to trees health and survivability. Therefore, there is a possibility that the wax degradation level can be used as an indicator for massive aerosol deposition. 


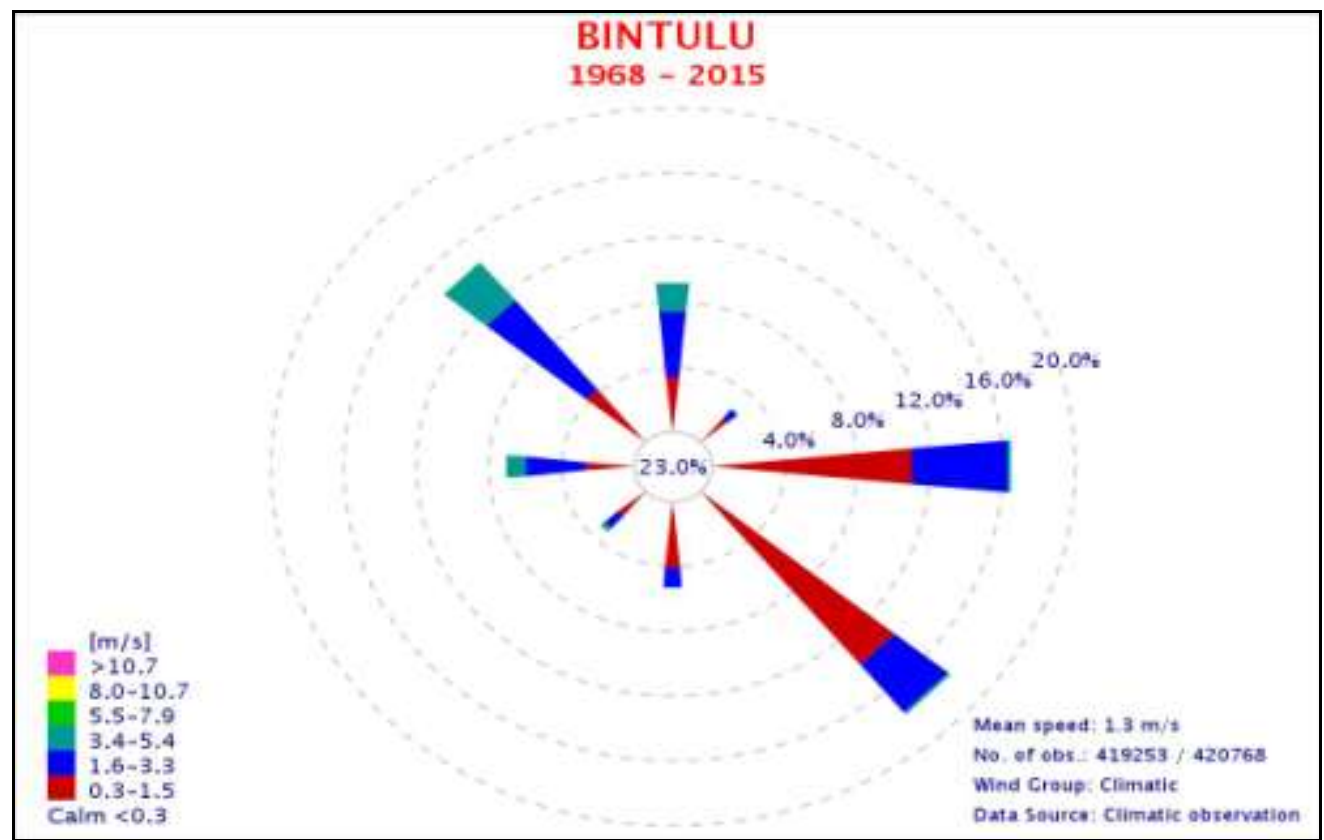

Figure 4. The wind rose chart for Bintulu

This initial study reveal that the level of physiological stress on the trees in industrial, suburban and urban areas are at a different scale. This could be due to the different levels of air pollution in these areas. Understanding the changes occurring at the epicuticular wax can help understand the types and level of pollutants in a locality. Some studies suggested that the wax structure can be used as an early indicator of traffic exposure effects $[14 ; 12]$. Apart from that, the epicuticular wax act as a receptor for the particulate matter. The capability of the trees depends on the microstructural like leaf rough surface, pubescence, thickness of epicuticular wax while macrostructural such as plant height, leaf arrangement and leaf areas $[33 ; 34 ; 35 ; 36]$. Therefore, to maximize the capabilities of the trees as bio filters, the relationship between these tree traits and environment should be articulated, yet at the moment this information is rather limited.

\section{Conclusion}

The setting created by industrialization and urbanization where vehicles and industries plays a significant role in decreasing the air quality. Urban plants are constantly exposure to the increasing level and types of pollutants. These pollutants will cause physiological stress to the trees which will appear in their plant's physical structure or physiology. Understanding, the tree traits are important to capitalize their role as bio filters. This study provide the baseline data for future study where the relationship with the particulate matters deposited on the tree canopy and the tree trait could be explained.

\section{Acknowledgments}

This study is supported through the Fundamental Research Grant Scheme (FRGS) under the Ministry of Education Malaysia (Project Code: 07-02-14-1600 FR). Research permit was granted by the Forest Department Sarawak (NCCD.907.44(Jld13)-101). We like to record our appreciation to Flora Avetia anak Vencent, Calson Gimang Bujang@Endawie and Andrea Tinggi who participated and contributed in the early field and laboratory works.

\section{References}

[1]. Pal A, Kulshreshtha K, Ahmad KJ, Behl HM. 2002. Do leaf surface characters play a role in plant resistance to auto-exhaust pollution? Flora 197, 47-55.

[2]. Sase H, Matsuda K, Visaratana T, Garivait H, Yamashita N, Kietvuttinon B, Hongthong B, Luangjame J, Khummongkol P, Shindo J, Endo T, Sato K, Uchiyama S, Miyazawa M, Nakata M, Wuled Lenggoro I. 2012. Deposition process of sulfate and elemental carbon in Japanese and Thai Forests. Asian Journal of Atmospheric Environment 6(4), 246-258.

[3]. Nakaba S, Yamane K, Fukahori M, Nugroho WD, Yamaguchi M, Kuroda K, Sano Y, Lenggoro W, Izuta T, Funada R. 2016. Effect of epicuticular wax crystals on the localization of artificially deposited sub-micron carbon-based aerosols on needles of Cryptomeria japonica. Journal of Plant Research. DOI 10.1007/s10265-016-0839-7.

[4]. Leonard RJ, McArthur C, Hochuli DF. 2016. Particulate matter deposition on roadside plants and the importance of leaf trait combinations. Urban Forestry and Urban Greening 20, 249-253.

[5]. Sase H, Takamatsu T. 2009. Atmospheric deposition and its leaf surface interactions in Japanese cedar forests. In Creighton JD, Roney PJ Eds. Forest canopies: forest production, ecosystem health and climate conditions. Nova Science Publishers. pp. 127-141. 
[6]. Terzaghi E, Wild E, Zacchello G, Cerabolini BEL, Jones KC, Di Guardo A. 2013. Forest Filter Effect: Role of leaves in capturing/releasing air particulate matter and its associated PAHs. Atmospheric Environment 74, 378-384.

[7]. Meusel I, Neinhuis C, Markstadter C, Barthlott W. 1999 Ultrastructure, chemical composition, and recrystallization of epicuticular waxes: transversely ridged roadles. Canadian Journal of Botany 77, 706-720.

[8]. Federle W, Maschwitz U, Fiala B, Riederer M, Hölldobler B. 1997. Slippery ant-plants and skilful climbers: selection and protection of specific ant partners by epicuticular wax blooms in Macaranga (Euphorbiaceae). Oecologia 112, $217-224$.

[9]. Markstadter C, Federle W, Jetter R, Riederer M, Holldobler B. 2000. Chemical composition of the slippery epicuticular wax blooms on Macaranga (Euphorbiaceae) ant-plants. Chemoecology 10, 033-040.

[10]. Barthlott W, Christoph Neinhuis C, Cutler D, Ditsch F, Meusel I, Theisen I, Wilhelmi H. 1997. Classification and terminology of Plant epicuticular waxes. Botanical Joumal of the Linnean Society 126, 237-260.

[11]. Francisco Sant'Anna-Santos B, Campos da Silva L, Alves Azevedo A, Marcos de Ara'ujo J, Figueiredo Alves E, Ant`onio Monteiro da Silva E, Rosane Aguiar R. 2006. Effects of simulated acid rain on the foliar micromorphology and anatomy of tree tropical species. Environmental and Experimental Botany 58, 158-168.

[12]. Turunen M, Huttunen S. 1990. A review of the response of epicuticular wax of conifer needles to air pollution. Journal of Environmental Quality 19(1), 35-36.

[13]. Burkhardt J, Pariyar S. 2014. Particulate pollutants are capable to 'degrade' epicuticular waxes and to decrease the drought tolerance of Scots pine (Pinus sylvestris L.). Environmental Pollution 184, 659-667.

[14]. Viskari E-L. 2000. Epicuticular wax of Norway spruce needles as indicator of traffic pollutant deposition. Water, Air and Soil Pollution 121, 327-337.

[15]. Turunen M, Huttunen S. 1991. Effect of simulated acid rain on the epicuticular wax of Scots pine needles under northerly condition. Canadian Journal of Botany 69, 412-419.

[16]. Mengel K, Hogrebe AMR, Esch A. 1989. Effect of acidic fog on needle surface and water relations of Picea abies. Physiologia Plantarum 75, 201-207.

[17]. Sase H, Takamatsu T, Yoshida T, Inubushi K. 1998. Changes in properties of epicuticular wax and the related water loss in Japanese cedar (Cryptomeria japonica) affected by anthropogenic environmental factors. Canadian Journal of Forest Research 28 , 546-556.

[18]. Said I, Omar Z, Cheng LF. 2004. Plant material Booklet 2: Wayside trees of Malaysia. Universiti Teknologi Malaysia, Skudai.

[19]. Abas MR, Bernd RT, Simoneie BRT. 1998. Wax Lipids from Leaf Surfaces of some common plants of Malaysia. Pertanika Journal of Science and Technology 6(2), $171-182$.

[20]. Alik E. 2008. Determination of N-alkanes in epicuticular waxes from leaf of three Litsea species and their chemotaxonomical significance. Bachelor Science Thesis, Universiti Malaysia Sarawak.

[21]. Post-Beittenmiller D. 1996. Biochemistry and molecular biology of wax production in plants. Annual Review of Plant Physiology and Plant Molecular Biology 47, 405-430.

[22]. Harrington CA, Carlson WC. 2015. Morphology and Accumulation of epicuticular wax on needles of Douglas-fir (Pseudotsuga menziesii var. menziesii) Northwest. Science 89(4), 401-408.

[23]. Department of Agriculture Sarawak. 2006. Sarawak Agriculture Statistics $2006 . \quad$ Available at http://www.doa.sarawak.gov.my/modules/web/pages.php?mod=webpage\&sub=page\&id=637.

[24]. Department of Agriculture Sarawak. 2013. Sarawak Agriculture Statistics $2013 . \quad$ Available at http://www.doa.sarawak.gov.my/modules/web/pages.php?mod=webpage\&sub=page\&id=712.

[25]. McWhorter CG. 1993. Epicuticular wax on johnsongrass (Sorghum halepense) leaves. Weed Science 41(3), 475-482.

[26]. Saneoka H, Ogata S. 1987. Relationship between water use efficiency and cuticular wax deposition in warm season forage crops grown under water deficit conditions. Soil Science Plant Nutrition 33, 439-448.

[27]. Rai PK. 2016. Impacts of particulate matter on plants: implications for environmental biomonitoring. Ecotoxicology and. Environmental Safety 129, 120-136. http://dx.doi.org/10.1016/j.ecoenv.2016.03.012.

[28]. Daresta BE, Italiano F, Gennaro GD, Trotta M, Tutino M, Veronico P. 2015. Atmospheric particulate matter (PM) effect on the growth of Solanum lycopersicum cv. Roma plants. Chemosphere 119, 37-42. http://dx.doi.org/10.1016/j.chemosphere.2014.05.054

[29]. Andrade GC, Silva LC. 2016. Protoplasma responses of tropical legumes from the Brazilian Atlantic Rainforest to simulated acid rain. DOI 10.1007/s00709-016-1054-z.

[30]. Burkhardt J, Peters K, Crossley A. 1995. The presence of structural surface waxes on coniferous needles affects the pattern of dry deposition of fine particles. Journal of Experimental Botany 46, 823-831.

[31]. Mulitza S, Heslop D, Pittauerova D, Fischer HW, Meyer I, Stuut JB, Zabel M, Mollenhauer G, Collins JA, Kuhnert H, Schulz M. 2010. Increase in African dust flux at the onset of commercial agriculture in the Sahel region. Nature 466, $226-228$.

[32]. Ravi S, D’Odorico P, Breshears DD, Field JP, Goudie AS, Huxman TE, Li JR, Okin GS, Swap RJ, Thomas AD, Van Pelt S, Whicker JJ, Zobeck TM. 2011. Aeolian processes and the biosphere. Reviews of Geophysics 49.

[33]. Mo L, Ma Z, Xu Y, Sun F, Lun X, Liu X, Chen J, Yu X. 2015. Assessing the capacity of plant species to accumulate particulate matter in Beijing, China. PLoS One 10 (10), e0140664, http://dx.doi.org/10.1371/journal.pone.0140664.

[34]. Nowak DJ, Crane DE, Stevens JC. 2006. Air pollution removal by urban trees and shrubs in the United States. Urban Forestry and Urban Greening 4 (3), 115-123. http://dx.doi.org/10.1016/j.ufug.2006.01.007.

[35]. Popek R, Gawronska H, Wrochna M, Gawronski SW, Saebø A. 2013.particulate matter of foliage of 13 woody species: deposition on surfaces and phytostabilisation in waxes - a 3-year study. International Journal of Phytoremediation 15 (3), 245256,http://dx.doi.org/10.1080/15226514.2012.694498.

[36]. Chaturvedi RK, Prasad S, Rana S, Obaidullah SM, Pandey V, Singh H. 2013. Effect of dust load on the leaf attributes of the tree species growing along the roadside. Environmental Monitoring Assessment 185 (1), 383-391. http://dx.doi.org/10.1007/s10661$012-2560-x$ 